\title{
CEPHALOMETRIC EVALUATION OF AIRWAY CHANGES FOLLOWING TWINBLOCK THERAPY IN CLASS II GROWING INDIVIDUALS
}

\author{
Dina Osman ElAbbasy*
}

\begin{abstract}
Objective: To evaluate changes in pharyngeal airway dimensions after treatment of Skeletal Class II with mandibular retrognathia using Twinblock functional appliance compared to Skeletal Class II untreated subjects.
\end{abstract}

Materials and Methods: 24 skeletal Class II patients with an age range 9-12 years old were selected from the outpatient clinic of the Department of Orthodontics, Cairo University. The patients were divided into two groups: a control group of untreated individuals (Group 1-Control, $n=12$ ) and a functional appliance group (Group 2-TwinBlock, $n=12$ ). Digital lateral cephalograms were made at the beginning (T1) and at the end of the observational period (T2) for Group 1 and at the end of the twinblock active treatment period for Group 2. Treatment duration in both groups was 7.5 months. Angular and linear lateral cephalometric measurements were done to identify skeletal relationship (SNA, SNB, ANB and Witts appraisal) as well as the widths of the upper and lower pharyngeal airways at T1 and T2 (Nasopharynx, oropharynx and hypopharynx). The data was evaluated and compared using Paired t-test and Independent sample t-test.

Results: The mean ages for Groups 1 and 2 were $10.53 \pm 1.32$ and $10.89 \pm 1.17$ years respectively. At T1, there were no statistically significant differences between the skeletal measurements and pharyngeal airway dimensions between the two study groups ( $p>0.05)$. However, at $\mathrm{T} 2$, statistically significant differences were observed between Groups 1 and 2 ( $p<0.05$ and $p<0.001)$ for all the skeletal and airway measurements with the exception of angle SNA and nasopharyngeal airway width whose changes were statistically insignificant $(\mathrm{p}>0.05)$.

Conclusions: Twinblock is effective in increasing the sagittal dimensions of the pharyngeal airway. Hence, this appliance can be useful in improving the respiratory function of growing individuals with reduced airway size due to mandibular deficiency.

\footnotetext{
* Lecturer Department of Orthodontics, Cairo University
} 


\section{INTRODUCTION}

Skeletal Class II malocclusion is one of the most common dentofacial anomalies and affects almost one third of the population. Etiology includes maxillary prognathism, mandibular retrognathism or a combination of both. Mandibular retrognathism has been reported to be the main cause (McNamara Jr, 1981 and Proffit et al, 1998 ).

Respiratory distress has frequently been reported in cases with mandibular retrusion due to the posterior position of the mandible and the tongue which leads to restriction of the pharyngeal region. These patients may be more prone to mouth breathing as a result of their reduced pharyngeal dimensions. There is a close relationship between the anatomy and function of the pharyngeal airways and craniofacial development (Cozza et al, 2008 and Ali et al, 2015a). Normal airway is one of the most important elements for the correct development of the craniofacial structures (Ansar et al, 2015).

Correction of Class II malocclusion involves forward positioning of the lower jaw and therefore can positively influence the airway dimensions. Hence, skeletal class II treatment is important for both aesthetics and functional purposes. Previous studies have investigated the changes that occur in the airway as a consequence of orthopedic treatment of skeletal class II by mandibular advancement (Goymen et al, 2019). Some found a positive correlation (Ozbek et al, 1998 and Ghodke et al, 2014) while others reported no significant changes in the airway following functional appliance treatment (Lin et al, 2011).

Some oral appliances whose mode of action are quite similar to functional appliances have long been suggested as a treatment option for obstructive sleep apnea to assist in opening the airway (Kushida et al, 2006 and Holley et al, 2011). The Twinblock appliance which was developed by William J Clark in 1970 is one of the most popular functional appliances and has proven effectiveness in promoting mandibular growth and can also be used as an aid in positively changing the airway dimensions (Abdelkarim , 2012; Sharma et el, 2012; Ghodke et al , 2014; Burhan \& Nawaya, 2015; Clark, 2015 and Elfeky \& Fayed, 2015).

Despite the various amount of research that investigated the effects of skeletal Class II correction by numerous functional appliances in growing patients, few studies examined the pharyngeal dimensional changes as a consequence to functional appliance therapy. This study was conducted to evaluate the efficiency of the twinblock appliance on the improvement of the upper and lower pharyngeal airway dimensions in skeletal Class II subjects with deficient mandible compared to an untreated control group.

\section{MATERIAL AND METHODS}

24 patients (10 males and 14 females) with Skeletal Class II malocclusion seeking orthodontic treatment were selected from the outpatient clinic of the Department of Orthodontics, Cairo University.

The following criteria were applied: (Figure 1)

1. Age range: 9-12 years old (circumpubertal)

2. Skeletal Class II malocclusion with mandibular deficiency and normal maxillary growth ANB angle $>4^{\circ}$ and Witts appraisal $>2 \mathrm{~mm}$

1. Overjet of at least $6 \mathrm{~mm}$

2. Bilateral Class II molar relationship

3. No or minimal crowding/spacing

4. Normal or hypodivergent facial pattern, FMA $\leq 25^{\circ}$

5. Upper incisors proclined and lower incisors upright or retroclined

6. No previous orthodontic/orthopedic treatment

7. No previous extractions

8. No respiratory problems or nasal obstructions

9. No past surgeries such as tonsillectomy

10. No syndromes, systemic illnesses, dental anomalies 


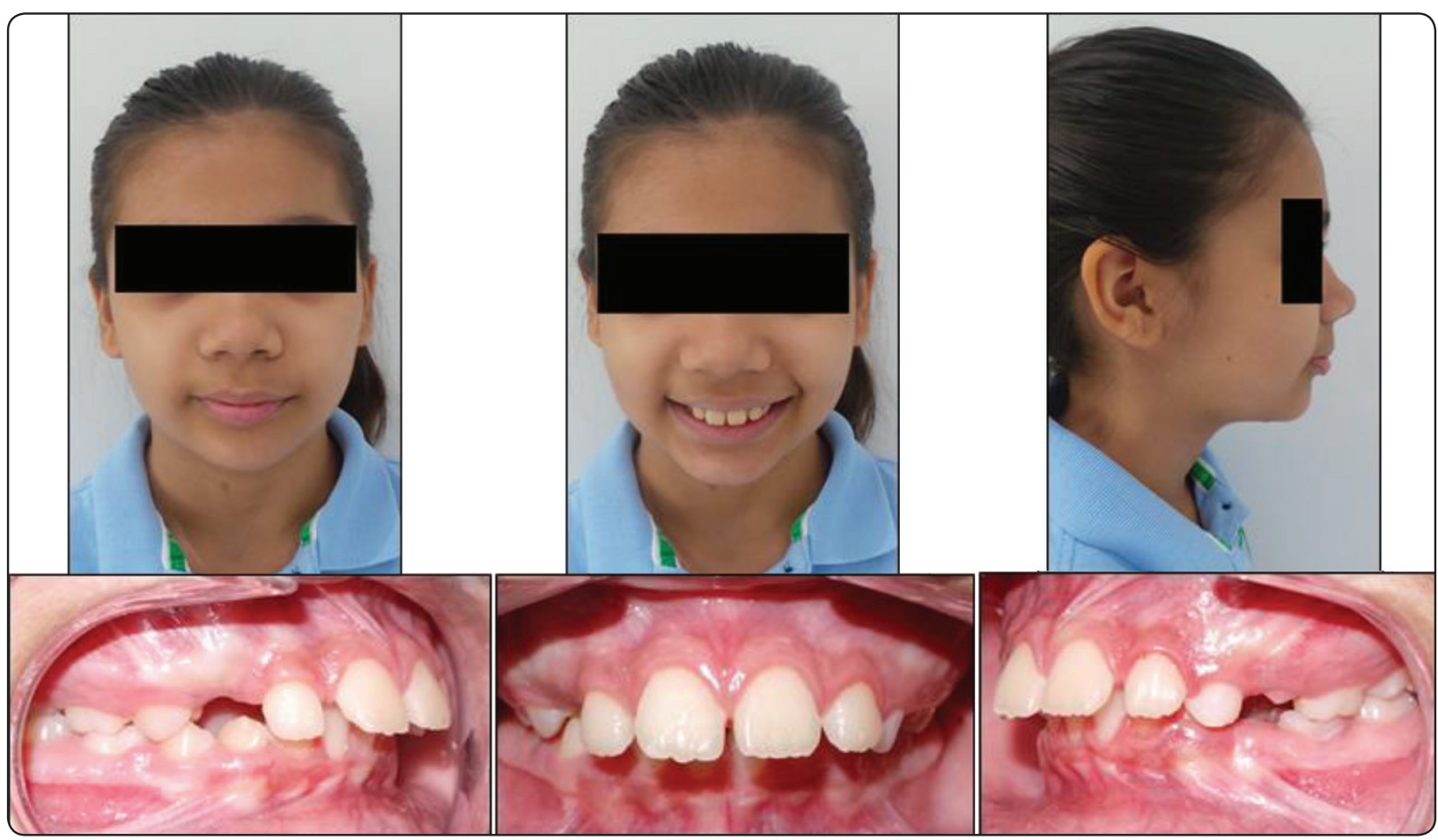

Fig. (1) Pretreatment photos for Group 2 patient (Twinblock group)

According to the type of treatment, the sample was divided into 2 groups: Group $1(\mathrm{n}=12)$ controls (7 males, 5 females) who received no treatment and Group $2(\mathrm{n}=12)$ who received Twinblock treatment (5 males, 7 females).

A written informed consent was signed by all the patients and the study was approved by the ethical committee of Faculty of Dentistry, Cairo University.

Lateral cephalograms were obtained for all patients at the beginning (T1) and at the end of the observational/treatment period (T2) 7.5 months later for the control group and the twinblock group. Lateral cephalograms were taken using a standardized technique with the same machine where patients were standing in the natural head position with the Frankfort Horizontal plane parallel to the floor and the teeth in centric occlusion. Patients were instructed to stand still and not move their heads or swallow during radiation exposure. The lateral cephalograms were traced using (CephX Imaging Software, USA) and the following points/ planes and landmarks were identified for skeletal measurements. The airway measurements were done according to the method implemented by Jena et al, 2012. (Figure 2)

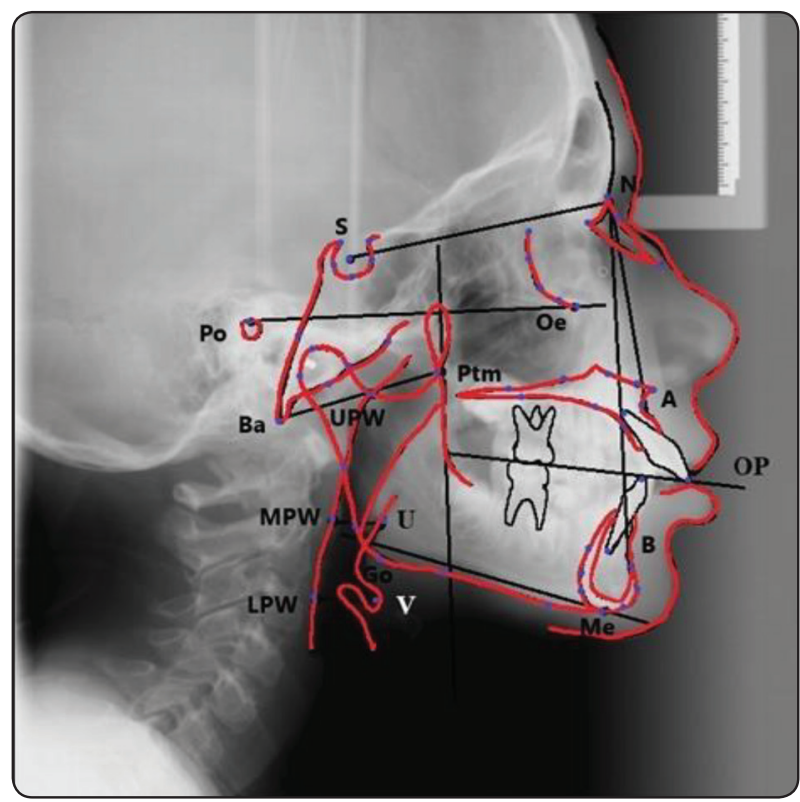

Fig. (2) N: Nasion; S: Sella; Po: Porion; Ba: Basion; Oe: Orbitale; Me: Menton; Go: Gonion; OP: Occlusal plane; Ptm: Pterygomaxillary fissure; U: Uvula; V: Vallecula; UPW: upper pharyngeal wall; MPW; middle pharyngeal wall; LPW: lower pharyngeal wall 
SNA: Angle formed between points Sella, Nasion and A point and describes anteroposterior position of the maxilla relative to the anterior cranial base

SNB: Angle formed between points Sella, Nasion and B point and describes anteroposterior position of the mandible relative to the anterior cranial bas

ANB: Angle formed between points A, Nasion and $B$ point indicating the skeletal relationship between the maxilla and the mandible

Witts appraisal: The linear distance between the perpendicular projections of points $\mathrm{A}$ and $\mathrm{B}$ over the functional occlusal plane.

FMA : Angle formed between mandibular plane and Frankfort horizontal plane

OP: occlusal plane

Ptm: pterygomaxillary fissure

Ba: Basion

U: tip of the soft palate

V: Vallecula

UPW- upper pharyngeal wall: Intersection of the line Ptm-Ba with posterior pharyngeal wall

MPW- middle pharyngeal wall: Intersection of perpendicular line on Ptm perpendicular from "U" with posterior pharyngeal wall.

LPW- lower pharyngeal wall: Intersection of perpendicular line on Ptm perpendicular from "V" with posterior pharyngeal wall.
The airway widths were measured as follows:

Nasopharyngeal airway width (NAW): The linear distance between Ptm and UPW.

Oropharyngeal airway width (OAW): The linear distance between U and MPW.

Hypopharyngeal airway width (HAW): The linear distance between $\mathrm{V}$ and LPW.

For assessing the intra-examiner reliability of measurements, 12 randomly selected lateral cephalograms were measured again after 2 weeks interval and statistical test was done to evaluate the accuracy of the measurements.

For construction of the Twinblock, waxbite registration was made for all patients whereby the mandible was advanced to achieve an edge to edge incisal relationship with a gap of 2-3 $\mathrm{mm}$ beyond the freeway space between the upper and lower central incisors. Advancement was done in one or two steps depending on the severity of the malocclusion (Figure 3). Instructions were given to wear the appliance 24/7 except during mealtimes. Followup was every 4 weeks for a total of 7.5 months. The patients in Group 2 were treated with Twinblock until Class I molar relation was achieved and the overjet reduced to $2 \mathrm{~mm}$ at the end of treatment.

\section{Statistics:}

All Data were collected, tabulated and subjected to statistical analysis. Statistical analysis was performed by SPSS in general (version 17), while Microsoft office Excel was used for data handling

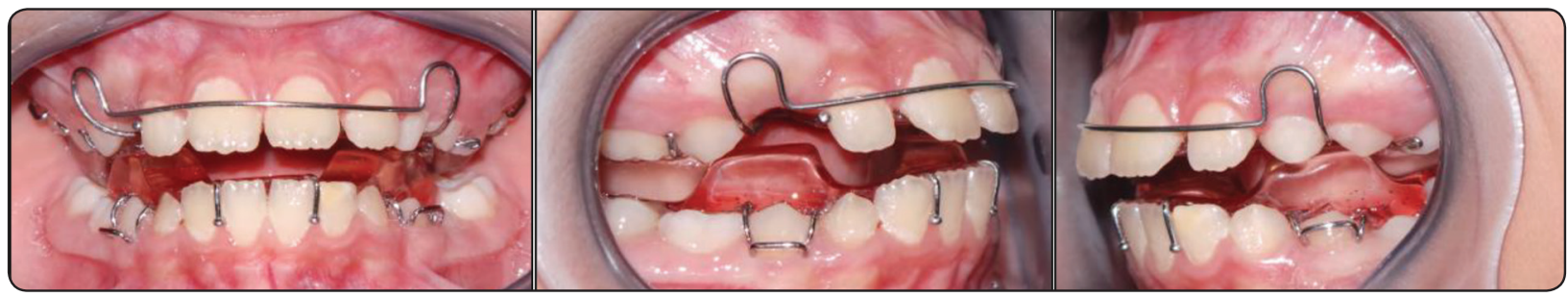

Fig. (3) Intraoral photos of the twinblock appliance 
and graphical presentation. Quantitative variables were described by the Mean, Standard Deviation (SD), the Range (Minimum - Maximum), Standard Error (SE) and 95\% confidence interval of the mean. Qualitative categorical variables were described by proportions and Percentages.

Shapiro-Wilk test of normality was used to test normality hypothesis of all quantitative variables for further choice of appropriate parametric and nonparametric tests. Mostly the variables were found normally distributed allowing the use of parametric tests. Paired samples t test was used for comparing the Post and Pre within each group. Independent samples $\mathbf{t}$ test was used for comparing the difference (Post-Pre) between the two groups. Chi-squared test was applied for 2 by 2 contingency table.

Significance level was considered at $\mathrm{P}<0.05$ (S); while for $\mathrm{P}<0.01$ was considered highly significant (HS). Two Tailed tests were assumed throughout the analysis for all statistical tests.

\section{RESULTS}

The mean ages of the patients at $\mathrm{T} 1$ in the control group and treatment group were $10.53 \pm 1.32$ and $10.89 \pm 1.17$ years respectively. No statistically significant differences existed between the mean ages of the two groups (Table 1). The mean duration of the treatment/observation period were 7.5 months for both groups. There was correction of the overjet and overbite. Posttreatment photos and lateral cephalogram for Twinblock group are shown in (Figure 4).

The distribution of gender between the two groups is shown in (Table 2). There was no statistically significant difference in the distribution of gender between the two groups. The mean intragroup values of the cephalometric analysis for the skeletal and airway measurements for both the treatment and the control group (intragroup differences) at $\mathrm{T} 1$ and T2 are shown in (Table 3).

Regarding intragroup comparisons, statistically significant differences were found for all skeletal and airway parameters within twinblock group at T2 compared to T1, with the exception of angle SNA and nasopharyngeal airway width (NAW) which showed no statistically significant changes ( $>0.05)$. For angle ANB as well as linear measurement Witts appraisal, there was statistically significant decrease $(\mathrm{p}<0.01)$ at the values $(-2.32 \pm$ $0.48)$ and $(-2.14 \pm 0.49)$ respectively. Angle SNB revealed a statistically significant increase between $\mathrm{T} 1$ and T2 ( $<0.01)$ at the value of $(1.52 \pm 0.64)$. FMA angle showed statistically significant increase at T2 $(1.09 \pm 0.72)(\mathrm{p}<0.01)$. Oropharyngeal and hypopharyngeal airway widths showed statistically significant increase between T1 and T2 $(\mathrm{p}<0.01)$ at the values of $(2.08 \pm 0.62)$ and $(1.73 \pm 0.71)$ respectively.

Within Group 1 (control group) there were no statistically significant differences between any of the variables at $\mathrm{T} 1$ and $\mathrm{T} 2(\mathrm{p}>0.05)$. SNB angle, FMA angle and lower pharyngeal airway showed mild increase in their values, which could be attributed to slight mandibular growth, however it was not statistically significant.

The mean changes between $\mathrm{T} 1$ and $\mathrm{T} 2$ and comparison of those changes between Group 1 and Group 2 (intergroup) are shown in Table 4. There were statistically significant differences between the two groups for all the parameters $(\mathrm{p}<0.01)$ with the exception of angle SNA and nasopharyngeal airway width (NAW) ( $>00.05)$. For intergroup comparisons, there were no statistically significant differences in the value of the cephalometric parameters between twinblock and control groups for all the skeletal and airway parameters at $\mathrm{T} 1(\mathrm{p}>0.05)$. For intra-examiner reliability of measurements, the correlation coefficient was 0.99 , which indicates that the measurements were reliable. 
TABLE (1) Independent samples $t$ test for comparing the mean ages between the two groups

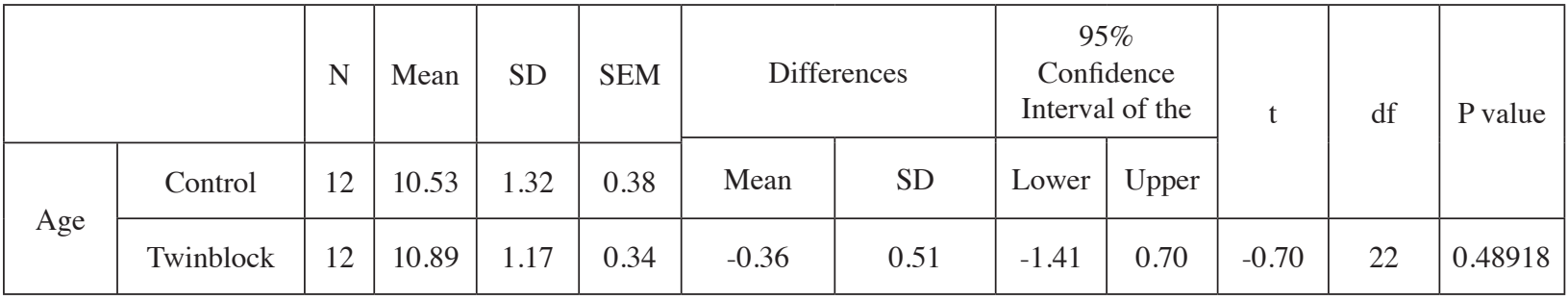

$P>0.05$ (Nonsignificant)

TABLE (2) Chi-squared test showing gender distribution between the two study groups

\begin{tabular}{|c|c|c|c|c|c|c|c|}
\hline \multirow{2}{*}{} & \multicolumn{2}{|c|}{ Males } & \multicolumn{2}{c|}{ Females } & \multirow{2}{*}{ Total } & \multirow{2}{*}{ Chi-Squared } & \multirow{2}{*}{ P value } \\
\cline { 2 - 6 } & Frequency & Percent & Frequency & Percent & & \multirow{2}{*}{0.67} & 0.41422 \\
\hline Control & 7 & $58.3 \%$ & 5 & $41.7 \%$ & 12 & 12 & \\
\hline Twinblock & 5 & $41.7 \%$ & 7 & $58.3 \%$ & 24 & & \\
\hline Total & 12 & $50.0 \%$ & 12 & $50.0 \%$ & 24 \\
\hline
\end{tabular}

$P>0.05$ (Nonsignificant)

TABLE (3) Paired t-test showing intragroup differences for Groups 1 and 2 at T1 and T2

\begin{tabular}{|c|c|c|c|c|c|c|}
\hline \multirow{3}{*}{ Parameters } & \multicolumn{5}{|c|}{ Groups } & \multirow{3}{*}{$\begin{array}{c}\text { Significance } \\
\text { (P-value) }\end{array}$} \\
\hline & \multicolumn{2}{|c|}{ Group 1 (Control) } & \multirow{2}{*}{$\begin{array}{c}\text { Significance } \\
\text { (P-value) }\end{array}$} & \multicolumn{2}{|c|}{ Group 2 (Twinblock) } & \\
\hline & $\begin{array}{c}\mathrm{T} 1 \\
\text { Mean } \pm \mathrm{SD}\end{array}$ & $\begin{array}{c}\mathrm{T} 2 \\
\text { Mean } \pm \text { SD }\end{array}$ & & $\begin{array}{c}\mathrm{T} 1 \\
\text { Mean } \pm \text { SD }\end{array}$ & $\begin{array}{c}\mathrm{T} 2 \\
\text { Mean } \pm \text { SD }\end{array}$ & \\
\hline $\mathrm{SNA}^{\circ}$ & $81.42 \pm 1.62$ & $81.6 \pm 1.41$ & 0.061 & $82.1 \pm 1.71$ & $81.34 \pm 1.78$ & 0.081 \\
\hline $\mathrm{SNB}^{\circ}$ & $75.88 \pm 1.16$ & $76.29 \pm 1.21$ & 0.068 & $75.68 \pm 1.66$ & $77.2 \pm 1.81$ & $0.000 * *$ \\
\hline $\mathrm{ANB}^{\circ}$ & $5.54 \pm 0.72$ & $5.31 \pm 0.55$ & 0.840 & $6.42 \pm 0.95$ & $4.1 \pm 0.79$ & $0.002 * *$ \\
\hline Witts (mm) & $3.44 \pm 1.17$ & $3.18 \pm 1.10$ & 0.481 & $3.58 \pm 1.04$ & $1.44 \pm 0.96$ & $0.009 * *$ \\
\hline $\mathrm{FMA}^{\circ}$ & $24.56 \pm 2.63$ & $24.91 \pm 2.74$ & 0.021 & $25.58 \pm 2.25$ & $26.67 \pm 2.54$ & $0.000 * *$ \\
\hline Nasopharynx (mm) & $12.72 \pm 5.33$ & $13.51 \pm 5.18$ & 0.251 & $12.08 \pm 5.21$ & $13.22 \pm 5.72$ & 0.064 \\
\hline Oropharynx (mm) & $9.48 \pm 2.05$ & $10.01 \pm 2.48$ & 0.48 & $9.25 \pm 2.13$ & $11.33 \pm 1.86$ & $0.000 * *$ \\
\hline Hypopharynx (mm) & $11.94 \pm 2.79$ & $12.61 \pm 2.16$ & 0.721 & $11.68 \pm 2.03$ & $13.41 \pm 2.14$ & $0.002 * *$ \\
\hline
\end{tabular}


TABLE (4) Independent sample t-test for comparing the difference (Post-Pre) between the two study groups

\begin{tabular}{|c|c|c|c|c|c|c|c|}
\hline \multirow[t]{2}{*}{ Parameter } & \multirow{2}{*}{$\begin{array}{c}\text { Group } 1 \text { (Control) } \\
\text { Mean } \pm \text { SD }\end{array}$} & \multirow{2}{*}{$\begin{array}{c}\text { Group } 2 \text { (TwinBlock) } \\
\text { Mean } \pm \text { SD }\end{array}$} & \multicolumn{2}{|c|}{ Differences } & \multicolumn{2}{|c|}{$\begin{array}{l}\text { 95\% Confidence } \\
\text { interval of the } \\
\text { difference }\end{array}$} & \multirow[t]{2}{*}{ P-Value } \\
\hline & & & Mean & $\mathrm{SD}$ & Lower & Upper & \\
\hline $\mathrm{SNA}^{\circ}$ & $0.2 \pm 0.19$ & $-0.76 \pm 0.33$ & 0.96 & 0.23 & 0.62 & 1.21 & $0.632(\mathrm{NS})$ \\
\hline $\mathrm{SNB}^{\circ}$ & $0.41 \pm 0.39$ & $1.52 \pm 0.64$ & -1.11 & 0.24 & -1.34 & -0.83 & $0.001 * *$ \\
\hline $\mathbf{A N B}^{\circ}$ & $-0.23 \pm 0.14$ & $-2.32 \pm 0.48$ & 2.09 & 0.14 & 1.53 & 2.12 & $0.000 * *$ \\
\hline Witts (mm) & $-0.26 \pm 0.18$ & $-2.14 \pm 0.49$ & 1.88 & 0.15 & 1.58 & 2.19 & $0.000 * *$ \\
\hline $\mathrm{FMA}^{\circ}$ & $0.35 \pm 0.36$ & $1.09 \pm 0.72$ & -0.74 & 0.20 & -0.93 & -0.55 & $0.004 * *$ \\
\hline NAW (mm) & $0.79 \pm 1.03$ & $1.14 \pm 0.92$ & -0.35 & 0.07 & -0.54 & -0.25 & 0.206 (NS) \\
\hline OAW (mm) & $0.53 \pm 0.89$ & $2.08 \pm 0.62$ & -1.55 & 0.10 & -1.83 & -1.43 & $0.000 * *$ \\
\hline HAW (mm) & $0.67 \pm 0.37$ & $1.73 \pm 0.71$ & -1.06 & 0.21 & -1.25 & 0.57 & $0.04 *$ \\
\hline
\end{tabular}

${ }^{*} P<0.05$ (Significant), **P<0.01 (Highly significant), $P>0.05$ (Non-Significant)

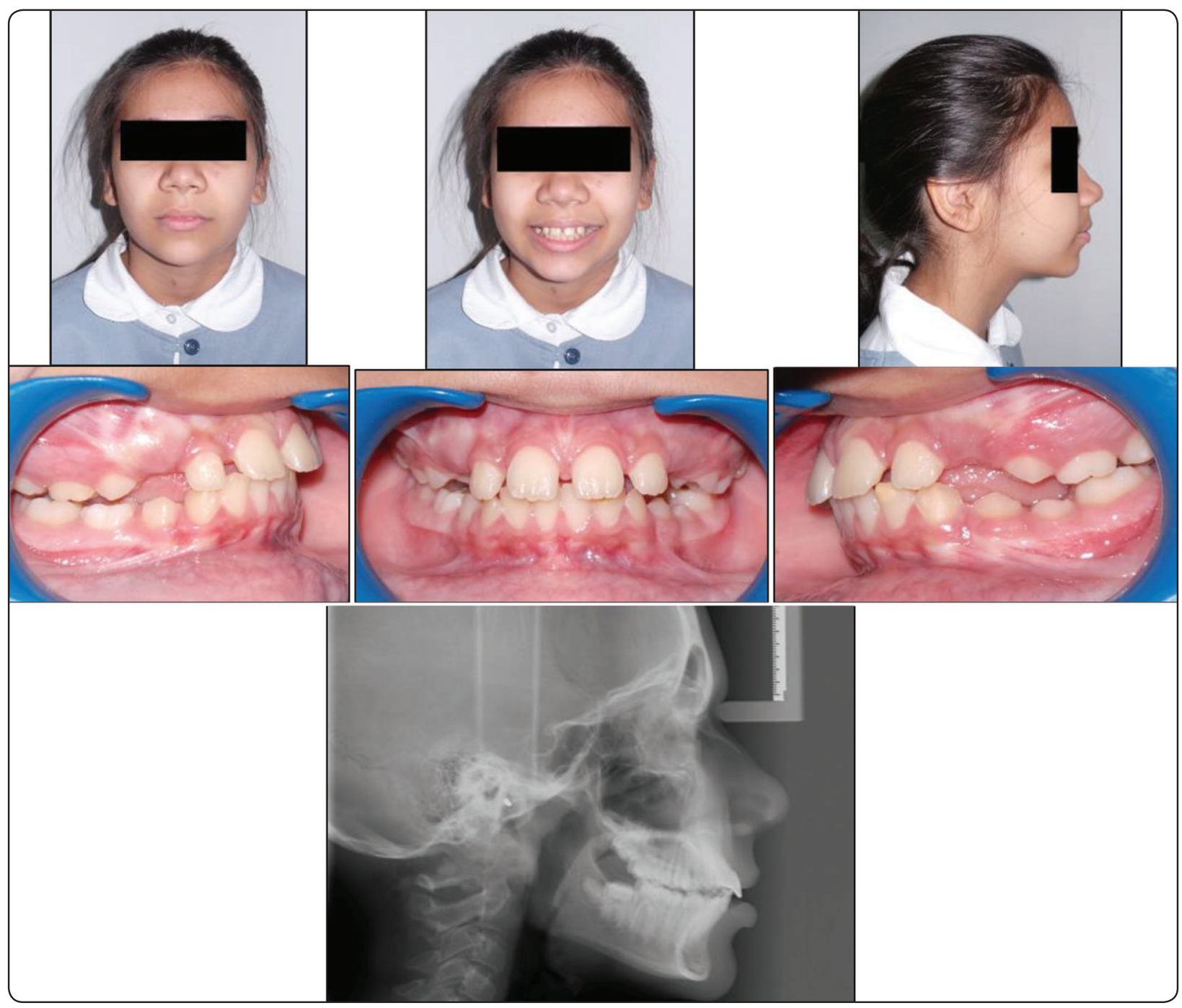

Fig. (4) Post-treatment photos and lateral cephalometry in Group 2 (Twinblock group) 


\section{DISCUSSION}

Twinblock is one of the most frequently used functional appliances for the treatment of skeletal class II malocclusion in growing individuals where mandibular deficiency is the primary etiological factor. Its mode of action is forward posturing of the mandible. It also exerts a resciprocal force on the maxilla in a distal direction thus restricting its growth while stimulating forward mandibular growth (Thapa et al, 2018). The use of functional appliances has also become more recommended as a treatment option for airway problems that result in obstructive sleep apnoea (Entrenas et al, 2019).

Pharyngeal airway dimensions have received a special interest in orthodontics and dentofacial orthopedics. It is well established that inadequate pharyngeal dimensions at a young age may induce sleep-disordered breathing at a later stage in life when the normal aging process due to age or obesity takes place and worsens an already narrowed pharyngeal airway dimension. Accordingly, it is highly valuable if modalities for correction of skeletal Class II can also lead to permanent increases in pharyngeal airway dimensions. In adults the option is surgical mandibular advancement while in young age it is functional appliance treatment (Ozbek et al, 1998 and Achilleos et al, 2000). A patent airway is believed to positively influence normal craniofacial growth and development as it promotes healthy sleeping patterns which accordingly lead to adequate release of plasma growth hormone which can stimulate condylar activity and enhance mandibular growth (Born et al, 1988).

The use of lateral cephalograms in this study is justified despite being a two-dimensional tool. It is a well documented modality for analysis of the airway where reproducibility of the measurements was found to be highly reliable (Malkoc et al, 2005) and has advantages over three-dimensional imaging such as lower cost and radiation dose as well as more availability (Susarla et al, 2010). Moreover, Aboudara et al, 2009 found a strong correlation between the size of the airway on lateral cephalometric films and the true volumetric size on cone beam computerized tomography scans.

Subjects with nasal obstruction or compromised airway were excluded from the study as patients who are mouth breathers may have reduced airway dimensions. Cases with hyperdivergent or vertical facial patterns were also excluded from the study as it has previously been reported that they suffer from an airway that is narrower than normal or hypodivergent ones (Zhong et al, 2010).

Subjects with skeletal Class II mandibular deficiency are expected to have a lower pharyngeal width that is smaller than healthy Class I malocclusion subjects (Ceylan \& Oktay, 1995 and Kirjavainen et al, 2007). This is due to the backward positioned mandible in skeletal Class II patients which results in airway narrowing. This backward mandibular position pushes the tongue and soft palate posteriorly and therefore decrease the dimension of the lower airway (Jena et al, 2010). In subjects where skeletal Class II was treated by the twinblock appliance, the results were similar to those of untreated healthy control subjects as reported by Jena et al, 2012. In the sample of this study no Class I controls were included and therefore comparisons were made between treated and untreated Class II controls and any growth changes were differentiated. Regarding nasopharyngeal airway width in Class II mandibular deficiency, it is not believed to be affected by the retruded mandibular position and therefore the values at $\mathrm{T} 1$ for both groups were similar to normal Class I controls (Jena et al, 2012). The nasopharyngeal values in this study are similar to those of a study made by Yousif, $2015(12.7 \pm 3.65 \mathrm{~mm})$ who included normal Class I subjects in their study of variation of airway depth with regards to skeletal pattern and found close correlation between skeletal Class II group with mandibular deficiency and Class I malocclusion concerning the nasopharyngeal width values .This confirms the theory that the nasopharynx is not affected by mandibular deficiency . 
No significant differences were found between males and females regarding the pharyngeal airway width. This is in agreement with the studies of (Grauer et al, 2009 and Zheng et al, 2014).

In this study, the pharyngeal airway dimensions were analyzed utilizing the methodology implemented by Jena et al, 2012. The airway was divided into 2 parts: the upper airway and the lower airway. The upper pharyngeal airway constituted the nasopharynx and the lower pharyngeal airway constituted the oropharynx and hypopharynx. This is in line with other studies by Ozbek et al; 1998; Ghodke et al, 2014 and Goymen et al, 2019. On the other hand, the study by Entrenas et al, 2019 employed McNamara's analysis (McNamara, 1984) for measuring the airway which divides it into upper pharynx (nasopharynx) and lower pharynx (oropharynx) only. No evaluation of the airway changes that occur in the structures in between is included. Furthermore, because an effect is expected to occur on the hypopharynx as well due to mandibular advancement, this parameter was included in this study. Additionally there is a great individual variation in determining the anterior half of the soft palate and the closest points on the posterior pharyngeal wall necessary to assess the nasopharynx in McNamara's analysis, therefore it might compromise the accuracy of the tracing. In the current study we aimed at using more stable bony landmarks such as the pterygomaxillary fissure and the basion to measure the nasopharyngeal width which can lead to better accuracy and reproducibility.

From the current study it was evident that the sagittal jaw relationship was significantly improved following twinblock treatment. This is documented by the significant increase in angle SNB $(+1.52 \pm$ $0.64)$ due to mandibular forward displacement. Witts appraisal showed statistically significant decrease $(-2.14 \pm 0.49)$ as well as angle ANB (-2.32 \pm 0.48$)$. The restriction on maxillary growth was evident in the decrease in angle SNA $(-0.76 \pm 0.33)$ even though it was non-significant statistically. This is in accordance with the results of the study by Jena \& Duggal, 2010; Ghodke et al, 2014 and Goymen et al, 2019 who reported similar mean changes. FMA angle showed a mild but statistically significant increase following twinblock treatment. This can

The values of nasopharyngeal, oropharyngeal and hypopharyngeal airway widths (NAW, OAW and HAW) respectively in both the control and treatment group were similar and comparable at T1. However, at T2 there were significant increases in the OAW and HAW in the twinblock group compared to the control group. This is well explained by the fact that forward positioning of the mandible by the functional appliance improves the hyoid bone position which advances the tongue due to the increased genioglossus muscle tone and thus improves the dimensions of the airway. OAW increase was of a mean value $2.08 \pm 0.62$ while hypopharyngeal width increased by $1.73 \pm 0.71 \mathrm{~mm}$. Similar results and values were reported by Ozbek et al, 1998; Achilleous et al, 2000; Zhou et al, 2000; Jena et al, 2012; Yassaei et al, 2012; Ghodke et al, 2014 and Entrenas et al, 2019. Schutz et al, 2011 in their three-dimensional study also discovered a volumetric increase in the width of the hypopharynx due to forward mandibular repositioning which occurred after class II treatment with Herbst. Xiang et al, 2017 emphasized that besides improving esthetics and function, Class II treatment can decrease the potential risk of obstructive sleep apnea in growing individuals during their adult life. This was also augmented by the results of Zha et al, 2008 and Cozza et al., 2008. In contrast to these studies was the study done by Kinzinger et al, 2011 who found functional appliance and herbst treatment unsuccessful in preventing breathing problems in high risk individuals. Moreover, Fastuca et al, 2014 observed no statistically significant improvement in the oropharyngeal airway measurements after mandibular advancement in maxillary expansion of growing subjects. 
In the treatment group, no significant changes were observed regarding the nasopharyngeal airway dimensions as previously noted by Jena et al, 2012; Ghodke et al, 2014 and Goymen et al, 2019. However, the results of Restrepo et al, 2011 were in disagreement with these results as they reported a statistically significant increase in the nasopharyngeal airway dimensions in skeletal Class II patients treated by bionator functional device. Entrenas et al, 2019 also reported an increase in the width of the nasopharyngeal airway following functional appliance therapty. This variation between their results and ours could be due to the different airway analysis and landmarks used.

Although some changes were observed in the control group for both skeletal and airway measurements at the end of the observational period, none of them were statistically significant. This is augmented by the results of Hanggi et al, 2008 who reported no changes in airway dimensions during adolescence. This might question the hypothesis of Ozbek et al, 1998 and Jena et al, 2012 who stated that improvement in airway width in mandibular deficient patients could be attributed to catching up growth whereby patients who suffer from narrow oropharyngeal dimensions develop an inherent stimulus to increase the respiratory function and therefore reveal increased airway dimensions without any need for treatment.

Accordingly this study confirms the hypothesis that functional appliance treatment can positively influence the pharyngeal airway dimensions and help treat breathing problems associated with skeletal Class II malocclusion with mandibular deficiency. Reports on stability of the changes in the long term have previously been supported (Hanggi et al, 2008 and Yassaei et al, 2012). The improvement in airway is mainly due to the soft tissue and muscular changes that accompany the sagittal jaw position. This can prevent mouth breathing habit which could negatively affect the developing occlusion and skeletal morphology. It can also eradicate causative factors of obstructive sleep apnoea in adult life.

\section{CONCLUSIONS}

1. There is a positive influence of twinblock functional appliance treatment on the lower pharyngeal airway width in growing individuals with mandibular deficiency and results in an increase in the sagittal dimensions of the oropharynx and hypopharynx.

2. No influence of functional appliance treatment on nasopharyngeal or upper pharyngeal airway width was observed.

\section{RECOMMENDATIONS}

Future studies should include large samples in order to create norms for pharyngeal airway dimensions for the Egyptian population as well as studying the variation of pharyngeal airway in different facial patterns.

\section{REFERENCES}

- Abdelkarim A. A cone beam CT evaluation of oropharyngeal airway space and its relationship to mandibular position and dentocraniofacial morphology. J World Fed Orthod. 2012;1: e55-e59

- Aboudara C, Nielsen I, Huang JC, Maki K, Miller AJ, Hatcher D. Comparison of airway space with conventional lateral head films and 3-dimensional reconstruction from cone- beam computed tomography. Am J Orthod Dentofac Orthop 2009; 135:468-79.

- Achilleos S, Krogstad O, Lyberg T. Surgical mandibular advancement and changes in uvuloglossopharyngeal morphology and head posture: a short- and long-term cephalometric study in males. Eur J Orthod. 2000; 22:367-381.

- $\quad$ Ali B, Shaikh A, Fida M. Changes in oropharyngeal airway dimensions after treatment with functional appliance in class II skeletal pattern. J Ayub Med Coll Abbottabad. 2015a ;27(4):759-63.

- $\quad$ Ansar J, Singth RK, Bhattacharya P, Agarwal DK, Verma SK, Sandhya M. Cephalometric evaluation of the airway dimensions in subjects with different growth patterns. J Orthod res. 2015;3 (2): 108-112.

- $\quad$ Born J, Muth S, Fehm HL.The significance of sleep onset and slow wave sleep for nocturnal release of growth 
hormone $(\mathrm{GH})$ and cortisol. Psychoneuroendocrinology. 1988;13(3):233-43.

- Burhan A, Nawaya F. Dentoskeletal effects of the bite jumping appliance and the twin-block appliance in the treatment of skeletal class II malocclusion: A randomized controlled trial. Eur J Orthod. 2015 Jun; 37(3):330-7.

- Ceylan I, Oktay H. A study on the pharyngeal size in different skeletal patterns. Am J Orthod Dentofac Orthop 1995; 108:69-75.

- Cozza P, Ballanti F, Castellano M, Fanucci E. Role of computed tomography in the evaluation of orthodontic treatment in adult patients with obstructive sleep apnea syndrome (OSA). Progress in orthodontics. 2008; 9(1): 6-16.

- Clark WJ. Twin block functional therapy: Application in dentofacial orthopaedics. New Delhi, India: JP Medical Publishers.

- $\quad$ Elfeky HY, Fayed MS. Three-dimensional effects of twinblock therapy on pharyngeal airway parameters in class II malocclusion patients. J World Fed Orthod. 2015;4 (3):114-119.

- Entrenas I., Gonzalez-Chamorro E, Alvarez-Abad C, Muriel J, Menendez-Diaz I, Cobo T. Evaluation of changes in the upper airway after twinblock treatment in patients with Class II malocclusion. Clin Exp Dent Res. 2019; 5:259-268.

- $\quad$ Fastuca R, Zecca PA, Caprioglio A. Role of mandibular displacement and airway size in improving breathing after rapid maxillary expansion. Prog Orthod. 2014; 15(1):40.

- $\quad$ Ghodke S, Utreja AK, Singh SP, Jena AK. Effects of twinblock appliance on the anatomy of pharyngeal airway passage (PAP) in class II malocclusion subjects. Progress Orthod. 2014; 15(1) :68.

- Göymen M, Mourad D, Güleç A. Evaluation of Airway Measurements in Class II Patients Following Functional Treatment. Turk J Orthod. 2019;32(1):6-10.

- Grauer D, Cevidanes LS, Styner MA, Ackerman JL, Proffit WR. Pharyngeal airway volume and shape from cone- beam computed tomography: relationship to facial morphology. Am J Orthod Dentofacial Orthop 2009;136: 805-14.

- Hänggi MP, Teuscher UM, Roos M, Peltomäki TA. Longterm changes in pharyngeal airway dimensions following activator-headgear and fixed appliance treatment. Eur J Orthod. 2008; 30: 598-605.

- Holley AB, Lettieri CJ, Shah AA. Efficacy of an adjustable oral appliance and comparison with continuous positive airway pressure for the treatment of obstructive sleep apnea syndrome. Chest. 2011;140(6): 1511-1516

- Jena AK, Duggal R. Treatment effects of twin-block and Mandibular Protraction Appliance-IV (MPA-IV) in the correction of Class II malocclusion. Angle Orthod. 2010;80(3): 485-491.

- Jena AK., Singh SP, Utreja AK. Effectiveness of twinblock and mandibular protraction appliance-IV in the improvement of pharyngeal airway passage dimensions in class II malocclusion subjects with a retrognathic mandible. Angle Orthod. 2012; 83(4): 728-734.

- Kinzinger G, Czapka K, Ludwig B, Glasl B, Gross U, Lisson J. Effects of fixed appliances in correcting Angle Class-II on the depth of the posterior airway space. J Orofac Orthop. 2011;72(4): 301-320.

- Kirjavainen M, Kirjavainen T. Upper airway dimensions in Class II malocclusion. Effects of headgear treatment. Angle Orthod. 2007;77(6): 1046-53.

- Kushida CA, Morgenthaler TI, Littner MR. Practice parameters for the treatment of snoring and obstructive sleep apnea with oral appliances: an update for 2005. Sleep. 2006;29(2): 240-243.

- $\quad$ Lin YC, Lin HC, Tsai HH. Changes in the pharyngeal airway and position of the hyoid bone after treatment with a modified bionator in growing patients with retrognathia. $\mathrm{J}$ Exp Clin Med. 2011;3(2): 93-8.

- Malkoc S, Usumez S, Nur M, Donaghy CE. Reproducibility of airway dimensions and tongue and hyoid positions on lateral cephalograms. Am J Orthod Dentofacial Orthop. 2005;128(4): 513-516.

- McNamara Jr JA. Components of Class II malocclusion in children 8-10 years of age. Angle Orthod. 1981;51(3): 177-202.

- McNamara JA Jr. A method of cephalometric evaluation. Am J Orthod Dentofacial Orthop. 1984; 86(6): 449-469.

- Ozbek M, Toygar Memikoglu U, Gögen H, Lowe AA, Baspinar E. Oropharyngeal airway dimensions and functional-orthopedic treatment in skeletal Class II cases. Angle Orthod. 1998;68(4): 327-36.

- $\quad$ Proffit R, Fields HW Jr., Moray LJ. Prevalence of malocclusion and orthodontic treatment need in the United States: Estimates from the NHANES III survey. Int J Adult Orthodon Orthognath Surg. 1998; 13(2):97-106.

- $\quad$ Restrepo C, Santamaria A, Pelaez S, Tapias A. Oropharyngeal airway dimensions after treatment with functional appliances in Class II retrognathic children. J Oral Rehabil. 2011;38(8): 588-594. 
- Schutz TCB, Dominguez GC, Hallinan MP, Cunha TCA, Tufik S. Class-II correction improves nocturnal breathing in adolescents. Angle Orthod. 2011;81(2): 222-228.

- Sharma AK, Sachdev V, Singla A, Kirtaniya BC. Skeletal and dentoalveolar changes concurrent to use of Twin Block appliance in class II division I cases with a deficient mandible: a cephalometric study. J Indian Soc Pedod Prev Dent. 2012 30(3): 218-26.

- Susarla SM, Abramson ZR, Dodson TB, Kaban LB. Cephalometric measurement of upper airway length correlates with the presence and severity of obstructive sleep apnea. J Oral Maxillofac Surg 2010;68(11): 2846-55.

- $\quad$ Thapa, V, Shrestha, A, Sherchan, P, Poudel, P, Joshi, L. Twin block appliance: Effect on pharyngeal airway. Journal of Kathmandu Medical College 2018; 7(4): 147-152.

- Xiang M, Hu B, Liu Y, Sun J, Song J. Changes in airway dimensions following functional appliances in growing patients with skeletal class II malocclusion: A systematic review and meta-analysis. Int J Pediatr Otorhinolaryngol. 2017 Jun; 97: 170-180.

- Yassaei S, Tabatabaei Z, Ghafurifard R. Stability of pharyngeal airway dimensions: tongue and hyoid changes after treatment with a functional appliance. Int J Orthod Milwaukee. 2012; 23(1) :9-15.

- Yousif AA. Evaluation of upper and lower pharyngeal airway in hypo and hyperdivergent Class I, II and III malocclusions in a group of Egyptian patients. Tanta Dental Journal 2015; 12 (4): 265-276.

- Zha D, Qiao L, Ge Y, Deng Z, Xue T, Liu Y, Qiu J. The MRI study of upper airway on obstructive sleep apnea hypopnea syndrome. Lin Chung Er Bi Yan Hou Tou Jing Wai Ke Za Zhi. 2008; 22(13):593-6.

- Zheng ZH, Yamaguchi T, Kurihara A, Li HF, Maki K. Three dimensional evaluation of upper airway in patients with different anteroposterior skeletal patterns. Orthod Craniofac Res 2014; 17(1):38-48.

- Zhong Z, Tang Z, Gao X, Zeng XL. A comparison study of upper airway among different skeletal craniofacial patterns in non snoring Chinese children. Angle Orthod 2010; 80(2) :267-74.

- Zhou L, Zhao Z, Lu D. The analysis of the changes of tongue shape and position, hyoid position in Class II, division 1 malocclusion treated with functional appliances (FR-I). Hua Xi Kou Qiang Yi Xue Za Zhi. 2000 Apr; 18(2): 123-5. 